\title{
Lean Six Sigma Methodology: The Nub to Boost the Public Healthcare System in Egypt
}

\author{
Dr. Wael Omran Aly \\ Associated professor of public administration \\ High institute of management sciences and foreign trade \\ New Cairo Academy - Egypt
}

Received: Dec. 12, 2019 Accepted: Jan. 17, 2020 Online published: Feb. 3, 2020

doi:10.5296/jpag.v10i1.16028～URL: https://doi.org/10.5296/jpag.v10i1.16028

\begin{abstract}
For many decades, the Egyptian people have suffered from deplorable public healthcare service featured by indolence, malfunction and traditionalism. Although, healthcare is a distinctive service industry concerning various complicated responsibilities; but the consecutive government of Egypt had badly handled such issue. Then, the apathetic performance of the public healthcare service becomes a dilemma for the people of Egypt; especially the poor among them. Therefore, the foundation of an adequate public healthcare service system, that respect the dignity of the people and respond to their arising health care needs; was frequently on the agenda priorities of the Egyptian governments after the 2011 and 2013 uprisings. Hence recently, the government -after reaching political and economic stability- seeks to build an ambitious newly public health care system to meet the expectation of the people to acquire high standard inexpensive and hasty public healthcare services. Consequently, in order to realize such aim; the Egyptian government had established the public agency for accreditation and quality control according to law no. 2 of comprehensive healthcare insurance system issued at 2018. Then, it urges a national campaign to reform the public healthcare sector and to develop the efficacy and quality of its services. Hence, this paper aims to propose how the public healthcare organizations in Egypt can tackle various challenges and enhance adequately its capabilities; in order to be able to adopt the proposed Lean Six Sigma (LSS) methodology effectively; which can then provide an adequate framework for creating organized improvement exertions in healthcare; necessary to bestow guidelines on how to manage a quality service system to patient satisfaction by decreasing waste, variation and work disparity in the service processes.
\end{abstract}

Keywords: lean six sigma, public healthcare service, quality improvement, patients satisfaction 


\section{Introduction}

Healthcare systems and divisions, all over the world, directing on-going stress to decrease all kinds of costs for its services from one flank, but also, on the other flank, to augment quality, minimize response, waiting and lead time, enhance patient safety; continually propose developed and valuable techniques and gears in daily performance. Those requirements embodies combined framework for healthcare management in developed and developing countries - as in the case of Egypt- in their quest for key answers, methods and techniques which will confirm fulfilment of all necessities and accomplishing of defined targets. Hence, Lean which removes the waste and Six Sigma which reduces the variation in hospital processes are consistent quality improvement instruments that can help to realize these aims. With recognized successes in business and industrial contexts; Lean Six Sigma is putting also its stain in healthcare. In just one instance, researchers using a Lean Six Sigma (LSS) approach successfully diminished intensive care unit (ICU) duration of remaining for patients with lengthy mechanical ventilation by $24 \%$ (from 29 days to 22 days). Costs per patient slumped $27 \%$ (from \$66,335 to \$48,370)(Lippincott Solutions, 2017; Graves, 2014). Then, the emphasis hereby will be on Lean Six Sigma methodology which involves the amalgamation of Lean Manufacturing and Six Sigma; where one instrument tackles Speed and wastes and other instrument tackles variation. So, comprehending lean six sigma methodology will help to build an adequate framework for creating effective organized innovation efforts in healthcare; essential to make health care services in utmost speed, fewer variation and enhanced productivity. Accordingly, such framework would be beneficial to the emerging public agency for accreditation and quality control - recently established at 2018 according to law no.2 for healthcare insurance - responsible for a wide range of public healthcare organizations in Egypt. Thus in this article, success factors that yield a maintainable process for improvement program in the Egyptian public healthcare services via the application of proposed lean sigma methodology are explored.

Thereby, this paper tends - via analytical descriptive methodology- to find the answer for the following research question: "How the proposed Lean Six Sigma methodology can be applied to boost the public healthcare system in Egypt"? Therefore, the researcher aims firstly to shed light on Lean approach significance. Secondly, Six Sigma conception is illustrated. Thirdly, the proposed framework for applying the integrated Lean Six Sigma methodology to healthcare system is presented in details. Finally, the main barriers to adopt such proposed framework at the Egyptian public healthcare service system are detected and some pillars to overcome effectively these barriers and lead to the adoption of LSS framework are recommended.

\section{Lean Approach Significance}

Lean thinking initiated at Toyota with the Toyota Production System (TPS). The genuine notions were crystallized by Sakichi Toyoda in the 1920s and 1930s. Taiichi Ohno started to apply these notions in the 1940s but only did the bound to complete application in the 1950s. Consequently, it has become the emphasis of many scientific writings, particularly a research accomplished by the Massachusetts Institute of Technology (Womack et al, 1991). Lean can 
be described as a management approach that pursues to amplify value to customers, both internal and external, while concurrently eliminating wasteful actions and performances. Although the word "waste" is regularly employed to depict a government program that does not lead to the complete welfare of society, here this term is exploited to signify the non-value-added usage of a service provider's time, for instance time expended fixing a previous error. Lean Thinking (Womack \& Jones, 2003) presented many specialists to Lean, implying a five-step implementation guide: (1) identify value from the customer's outlook, (2) detect the stream of processes employed to deliver value, (3) eliminate non-value-added activities from the value stream, (4) produce pull by making all work originated by customer request, and (5) pursue for perfection. These steps would normally be executed during a one-to-five-day exertion called "kaizen", where a diverse stakeholder project team would work full time on the project, habitually leaded by a proficient facilitator known as a "sensei" (Maleyeff, 2014). It is notable to say, that numerous of the principles of lean originated from an unexpected basis: American supermarkets; where minor quantities of a huge assortment of inventory are restocked as customers "pull" them off the shelf. This is the Kanban system (Mehdi, 2005).

Then, the propagation of Lean Thinking was enabled by the book of Womack, Jones, and Roos (1990). Lean, as it is frequently shortened, signifies a vital disruption with Western industrial traditional customs. Therefore, Toyota and other Japanese companies elaborated Lean Thinking as an alternate pattern. Lean is a combined structure of principles, actions, instruments, and methods concentrated on diminishing waste, harmonizing work streams, and handling inconsistency in production flows. A crucial difference in Lean is among value- and non-value-added activities. Value added activities yield what the customer desires from a product or service (George, 2003). All the other activities are non-value-added activities. The main analytic instrument in Lean is the value-stream map, a prolonged progression flowchart with gen about speediness, continuance of flow, and toil in development. This instrument emphasizes non-value-added stages and blockages; and is exploited to conduct quality improvement (QI) activities. The value-stream map offers a comprehensive image of the whole value chain in an enterprise.

Furthermore, Lean proposes several typical solutions to communal organizational hitches. Visual management, complexity reduction, $5 \mathrm{~S}$ (a method for arranging the workplace: sort, straighten, shine, standardize, sustain), cellular production, pull systems, line balancing, one-piece flow, and single-minute exchange of dies (SMED) are some of the more common solutions (Shingo, 1989; Womack \& Jones, 2003). Lean's forte resides in its array of typical solutions to communal problems and its concentration on the customer. Lean pursues to realize optimum status by its emphasis on the whole value chain (George, 2003; Standard \& Davis, 1999). The most difficult fragment of learning to consider lean is deserting ancient notions about economies of scale and mass production. These are essentially "push" systems built on estimated customer need (Maleyeff, 2006). In lean, quality, productivity and low cost derive from yielding little lots (perfectly one) of a particular product, beginning-to-end without any loads of partly finished products. The tenets of lean are quite easy, whether they are applied to manufacturing, service, or administration (George, 2003). 
Nowadays lean notion is broadly acknowledged and applied array of instruments, techniques and methods in several firms all over the world (Bortolotti et al., 2015). In its core lean signifies a logical methodology to management, concentrated on recognition and removal of all kinds of waste and lost and on-going enhancement (Womack et al., 2003). Outcomes of positively presented lean conception could be assessed by improved value in production and enterprise processes, reorganized and arranged to give customers precisely what they desire in correspondence with augmented quality, enhanced safety, diminution of postponements and breakdowns. From its merely manufacturing basis lean notion discovered its path to further sectors and disciplines. Healthcare, as crucial and complicated sector in each community acknowledged the importance and the advantages of lean application; and nowadays consider as one of the most favourable and potential areas for additional development in many of concerned hospitals and healthcare sections from one part and diversity of employed instruments, approaches and methods from other part (Mazzocato et al., 2010; Fairbanks, 2007). It is noteworthy to ensure, that effectively using Lean necessitates a lasting lookout that ponders all stakeholders, mutually internally and externally. Thus, Lean will solely thrive if the organization's substructure signifies a communal emphasis (Monden, 1993).

\section{Six Sigma Conception}

Six Sigma was initially originated in the mid-1980s by Motorola as a quality control technique to preclude flaws in their industrial process (Folaron, 2003) and has been developed into a project-driven management methodology to enhance the organization's products, services, and operations by constantly diminishing shortcomings in the firm (Kwak et al., 2006). It was additionally evolved by General Electric in the late 1990s (Breyfogle, 1999; De Koning \& De Mast, 2006; Harry, 1997; Pyzdek, 2001). The Six Sigma methodology is featured by its customer-driven tactic, focus on decision making relied on keen analysis of quantitative data, and a primacy on cost lessening (Bisgaard \& Freiesleben, 2004; Kowalik, 2018). Six Sigma is employed by implementing enhancement projects. Project choice is mostly founded on a conversion of the organization strategy into operational targets (Pyzdek, 2004). Six Sigma delivers an organizational arrangement of project leaders and project owners. Project leaders are named Black Belts (BBs) and Green Belts (GBs). Employees of higher management level play the part of project owners, or Champions.

Then, Six Sigma is delineated in a diversity of manners by numerous writers. From a statistical viewpoint, Six Sigma is described by Motorola as a quality enhancement method with a goal of decreasing the amount of flaws to as minor as 3.4 parts per million chances (Henderson \& Evans, 2000). From a business viewpoint, Six Sigma is described as a firm strategy employed to enhance firm productivity and to develop the effectiveness and efficiency of all processes to encounter or surpass the consumer's desires and expectancies (Antony\& Banuelas, 2001).Three manifestations are significantly related with Six Sigma application: Six Sigma role configuration, Six Sigma organized enhancement process, and Six Sigma emphasis on metrics ( $\mathrm{Zu}$ et al., 2008). The role configuration of Six Sigma is regularly signified to as the "belt system". Six Sigma recognizes numerous main functions and roles for its enhancement experts: champions, master black belts, black belts, and green 
belts (Linderman et al., 2007). Those professional experts are allotted various echelons of roles and responsibilities to collaborate jointly in a ranked synchronized tool via various organizational levels to accomplish the Six Sigma goals (Harry \& Schroeder, 2006).

Consequently, Six Sigma employs two key organized techniques for development known as DMAIC (define-measure-analyze-improve-control) and DMADV (define-measure-analyze design-verify). The DMAIC technique is utilized for process enhancement (Schroeder et al., 2007); while the DMADV is employed for product and process design (Cronemyr, 2007). The focus of the DMAIC technique is the five-staged procedural structure that leads the enhancement project (Shankar, 2009;Pyzdek \& Keller, 2014).In the first four stages, numerous managerial and statistical instruments are utilized in a way that renders it easy to comprehend the process and its concerns along with finding the appropriate root causes of the problem and to come with the convenient solutions (Al-Qatawneh et al., 2019). The last stage confirms that the root causes of the problem are removed and the process will never return to its former bad status; as clarified below (Raghu \& Geo, 2017):

Define: this step identifies who the customers are, what the customers want, the process abilities, and states objectives for project-based enhancement exertions.

Measure: this step determines the quality features that embody enhancement in customer satisfaction and product performing and propose the measurements of data that the enhancement exertions will be relied upon.

Analyze: in this step, data gathered in former steps are analyzed employing analytical instruments such as Pareto analysis, process flow diagram, fish-bone diagram, statistical process control charts, for recognizing essential design and process adjustments for realizing customer satisfaction and performance objectives.

Improve: in this step resources are allotted then design and process adjustments needed for enhancement can be applied.

Control: in this step the process is monitored using quality management instruments such as Pareto charts, and statistical process control charts to certify that the performance enhancements are upheld.

To ensure an effective take-off and use of Six Sigma, an organizational infrastructure is made. For instance, an operational plan for strategic pertinent projects assures an association of project objectives with the long-term organizational goals (De Koning et al., 2006). Moreover, Six Sigma utilizes a stage-gate method to project management whereby projects are supervised prudently by Champions and proper acts are considered if a project does not encounter specific fulfilment dates. One apparent weakness of Six Sigma methodology is its intricacy. In the instance of tiny problems with apparent and simple-to-apply solutions, severe devotion to the Six Sigma problem-solving method could be pondered excess and incompetent (George, 2003). Then, Six Sigma normally does not turn to typical solutions to usual hitches as does Lean. Finally, the hazard of enhancing a process, while neglecting the whole value chain, always exists. However, Six Sigma proposes an organized, analytical, and logical comprehensive methodology to problem solving, along with a robust organizational 
setting for its application.

\section{Lean Six Sigma Framework to Healthcare Services}

Lean delivers an entire system approach but is brief on particulars, organizational charts, and logical instrument for analysis. Six Sigma, on the other hand, proposes less typical solutions but delivers an overall analytical framework for problem solving and an organizational substructure (De Koning et al., 2006). In spite of their contrasting origins, it is obvious that Six Sigma and Lean include numerous communal characteristics, such as focus on customer satisfaction, a culture of on-going enhancement, the quest for root causes, and complete employee participation. In each instance, an elevated level of training and education occurs, from the top management to the lower one. However, it is evenly apparent that disparities subsist. Lean managers are likely to be rather comprehensive, content with eliminating lavish activities that impede their capability to satisfy customers. On the other hand, Six Sigma managers are likely to be financially shoved, concentrating frankly on cost reductions or revenue growths as the standards for success (Maleyeff, 2014).Then, the optimum solution is to merge the two methodologies to reach an interaction that delivers outcomes far superior than if every methodology was applied separately. When Lean is combined to Six Sigma, sluggish processes are confronted and substituted with further rationalized workflows (see figure 1).

Furthermore, the data collected throughout Lean Flow application aids to recognize the Six Sigma opportunities with maximum influence. When Six Sigma is complemented to Lean, a far-desired structure is afforded that renders it simpler to reliably and possibly attain ideal stream (Raghu \& Geo, 2017). The two approaches operate jointly very good, that a novel, combined, Lean Six Sigma methodology, with its distinctive features, has been delineated and combined by many prominent organizations. Many experts have done so implicitly for rather some time. A combined effective framework for Lean Six Sigma methodology had to encompass the subsequent essentials (De Koning et al., 2006):

- An organized method: The employment sub structure is relied on Six Sigma organizational tools comprising of a task force employment strategy by BBs, GBs, and Champions.

- Project-based employment: A project is an enduring problem programmed for resolution (Juran, 1989). Projects are categorized by way of whether "hasty wins" (Lean) or "advanced" (Six Sigma). Lean projects pertain best performances and concentrate on applying typical solutions. Such projects normally include speediness, decrease of lead time; inventory, and processing time. Thus, Six Sigma projects relate to more broad and complicated problems and implicate concrete, data-based analytical approaches and statistics, involving quality improvement (QI) and control techniques. The problem-solving process of DMAIC is constantly employed, and projects are checked after each stage is fulfilled. Standard Six Sigma projects include boosting quality, reducing flaws, decreasing variation, and augmenting revenue but more commonly implicate structured improvement process (Bisgaard \& De Mast, 2006).

- Organizational capability advancement: Devoted staffs of Lean Six Sigma project leaders 


\section{Macrothink}

Journal of Public Administration and Governance ISSN 2161-7104

(Champions, GBs, and BBs) are developed in a context that is similar to Six Sigma with further Lean modules.

- Organizational affixing of solutions: To ensure the execution of solutions and protect counter to lapsing, duties and responsibilities are obviously stated, procedures are structured, and process controls are enforced as part of an enhancement project.

- Combining strategy with project choice: Strategic goals are converted into performance metrics and tactical objectives. These are thus employed as a foundation for project choice and aid to fortify an association of projects with the whole organizational strategy. It is simple to envisage multiple kinds of Lean Six Sigma.

A kind of such LSS framework delivered here would trigger the organization to (Maleyeff, 2014): (1) uphold an awareness of both internal and external customers' needs and wants, (2) pursue to boost the value-added substance of all processes, (3) continually assess employee inducements to certify their association with the overall performance objectives, and (4) behold a far severely financially calculable cost reductions.
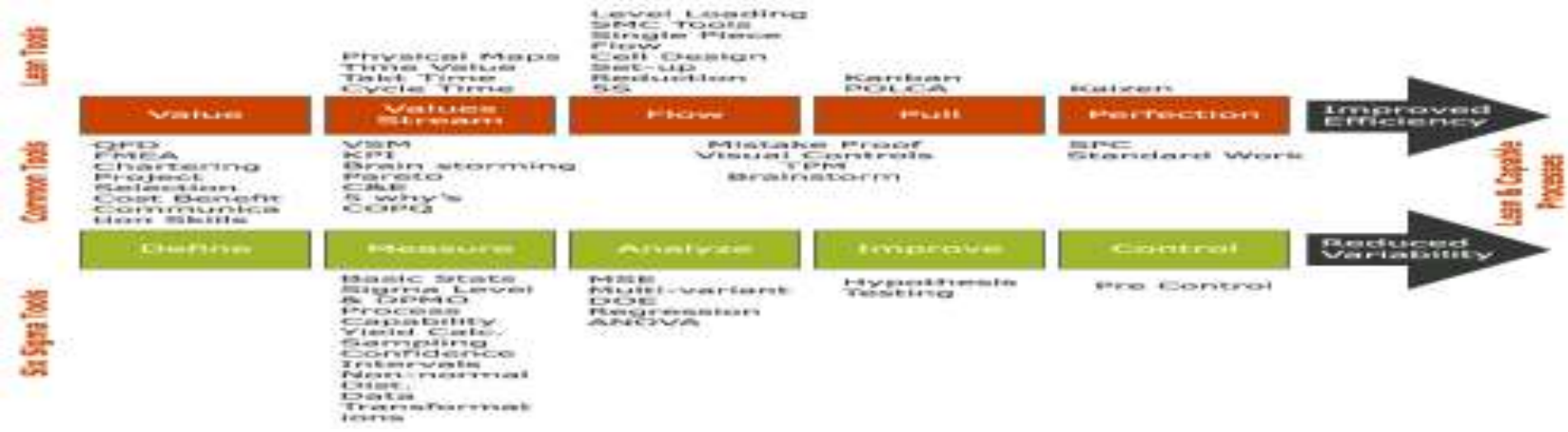

Figure 1. Lean Six Sigma Framework to health care services

Source: Mehdi, 2005.

Accordingly from a health care viewpoint, the combination of lean and Six Sigma - as it appears in figure 1- are meaningfully beneficial. What lean offers is hasty reduction of delivery blockages and needless activity in a particular process. Six Sigma imposes a data-centric strictness that produces greater quality and improved products. The hoax is to recognize how much enhancement to use before it becomes noxious to the lowest line (Gottfredson \& Aspinall, 2005). It is no accident that the achievements of lean and Six Sigma process creativities are appliance identifiable. The most apparent tendency in the literature proposes that lean-based programs pose a greater boom for the responsibility than contending Six Sigma activities. The differentiation is where each of the methodology is implemented. Complicated processes such as pharmacy operations and patient release fit justly to the intricate requirements of Six Sigma. Blockages in laboratory and surgical operations are more successfully managed with lean techniques. The writings also propose that 'leaning' processes encompassing patients (and people), encountered or surpassed the program expenses further than Six Sigma programs. In most instances, lean brought rapider results and was faster to market than Six Sigma (American Society for Quality, 2009). 


\section{Mll Macrothink}

Journal of Public Administration and Governance ISSN 2161-7104 2020, Vol. 10, No. 1

Then, the main differentiation was endurance of outcomes over an extended period. Lean offered less techniques of persistence as dependable as Six Sigma (Baczewski, 2005). Six Sigma process improvement (PI) projects set a considerable time and financial obligation for any organization. Therefore, it is vital for executive management to completely reinforce the program and constantly advocate its budget. It is correspondingly crucial to wisely analyze the likely cost against profits of each responsibility. For-benefit operations are further possible to restrict a complicated PI program short owing to the absence of an instant reimbursement-deriving from inadequately appointed anticipations (Al-Qatawneh et al., 2019).The appropriate recommendation to tackle the profit issues is to handle with lean and Six Sigma; therefore the financial consequence is strengthened. Whereby lean offers speeder results releasing funds to employ Six Sigma techniques and develop impetus for its constant obligation to change (Snee, R.D., 2005). Lean and Six Sigma are possibly the most thorough methodologies obtainable to fight decreasing limits in intensive care sets hospitals. To fund performance, Medicare revamps to face the risk of a lone pay or environment necessitated resources to remove waste at all levels to hinder financial loss (Yaduvanshi et al., 2017). The literature analysis apparently shows why the two methodologies are too persuasive in their relevant intensive care appliances. The health care service is on the rib of drastic alteration on the financing part that will diminish repayments. Organizations that do not enhance care and avoid process waste simultaneously will undergo financial subsistence contests (Charles, J. et al., 2008). The deficiency of an exact and comprehensive methodology as a compound paradigm of Six Sigma and lean methods for the whole hospital operations is missing around the world and its significance in the resource inadequate allocation in developing countries setting - as in the Egyptian case - is more restricted.

In a nut shell, Lean Six Sigma has lately been employed in the healthcare sector. George (2003), for instance, illustrates leading work on Lean Six Sigma at Stanford Hospital and Clinics and at the Red Cross Hospital in the Netherlands. The writings on LSS are developed with achievement stories showing convincing financial revenues and substantial operational enhancements. Gathering instances by precise part of enhancement appeared suitable in founding deepness and broadness, along with encouraging program analogy from one instance to the next instance. Moreover, the LSS literatures main topics involve: patient release and length of stay (LOS); emergency department (ED); operating room Flow and scheduling; hospital laboratory; diagnostic imaging (radiology); revenue cycle; and supply chain management (Yaduvanshi et al., 2017).

\section{Lean Six Sigma Framework to the Egyptian Health Care System: Barriers and Requirements}

The Egyptian healthcare system is fighting to retort to the growing patient numbers, whereas the devoted resources to healthcare are very restricted. Public hospitals are inadequate regarding patient burden. Statistics in 2015 indicate that there are on average 1.57 beds and 5.75 doctors in public hospitals for each 1000 patients (CAPMAS, 2017). Therefore, the foundation of an adequate public healthcare service system, that respect the dignity of the people and respond to their arising health care needs; was frequently on the agenda priorities of the Egyptian governments after the 2011 and 2013 uprisings. Then, the proposed Lean 
sigma framework can be the panacea for the Egyptian public healthcare dilemma. Unfortunately, many barriers hinder the ability of the Egyptian public healthcare system to adopt the proposed Lean Six Sigma (LSS) framework effectively. Therefore, Lean Six Sigma adoption is still in its initial phase in public healthcare at Egypt; as the Egyptian healthcare system still facing such various barriers that yield the incapability to maintain enhancements. Then, some essential requirements (reforming policies) had to be existed to overcome such barriers and ease the application of LSS framework to the Egyptian public healthcare system.

\subsection{Barriers to LSS Framework Adoption}

Many barriers surround the Egyptian public healthcare system and affect its ability to adopt an explicit policy to apply the proposed lean six sigma framework. Such barriers are as follows:

Legal barriers: Despite the establishment of the emerging public agency for accreditation and quality control according to the newly law no.2 of comprehensive healthcare insurance system issued at 2018; its role is blurring and the Egyptian public healthcare services organizations are still managed in the context of various laws and regulations. Such complicated legal environment cripples the quality development of the public healthcare services organizations whereby the majority of these laws are contradicted and not responding to changing circumstances of the community environment and the dynamic needs of the citizens/patients. Consequently, it causes a broad cynicism of government backing to the quality of health care service, unique human resource performances, medical staff permanency and job security matters, legislative controlling to health care performance, and conflicting particular interests (Maleyeff, 2014).

Financial barriers: Weak financial backing around 5\% of the total government budget in the fiscal year 2018-2019 is directed to the public healthcare service institutes in Egypt; thus their capability to maintain enhancements and to employ suitable quality method as lean six sigma methodology is very restricted (Radwan, 2018).

Institutional barriers: The exceeding denseness of public hospitals. Along with the formal registers, Egypt has an entire number of 660 public and 1002 private hospitals serve up overall populace of about91 million (CAPMAS, 2017), which yields a huge patient burden and limitless lines of patients who constantly linger extended hours for their consultation.

Human resource barriers: As stated by the World Health Organization (WHO), the obtainable nurses in Egypt are not only low in numbers, but they are badly qualified, where the total figure of skilled nurses was just 300,000 in 2011(World Health Organization, 2011). Furthermore, Egyptian medics are poorly paid and frequently turn to arguable exterior ways to improve their earnings by looking for work in private institutes beside their work in public hospitals or work overseas, which causes acute grievances about the restricted obtain ability of medical consultants in public hospitals and clinics. Moreover, the medical workforce mourns from mismanaging their knowledge, abilities and aptitudes to improve the activities of the public healthcare service (Zineldin, 2006).

Scarcity of healthcare Quality research: Latest literatures disclosed the dearth of research 
that examines the service quality offered by Egyptian hospitals. Mostafa (2005) explored the patients' insights and prospects of the service quality delivered by public and private hospitals in Egypt, which is crucial to comprehend the association amid quality of care and the use of health services. Those diminutive researches only have emphasized on evaluating and handling hospitals' service quality in the Arab world, and Egypt is no exclusion. They infer that patients of public Egyptian hospitals are not satisfied as patients of private ones, which gain profit through forceful marketing and pricing strategies (Mostafa, 2005).

Managerial and Organizational barriers: The Egyptian public health care services organizations suffers from enormous deplorable structure featured by rigidity, centralization, crippled red tapes, duplicate documents, repetition of procedures and examinations, elusive accountability, paralyzed communication channels, untrained mediocre employees, medical staff (nurses and doctors) unable to apply advanced quantitative methods, and many undocumented processes (Zineldin, 2006). Furthermore, they are grieving from low wage as well as low morality. Such apathetic bureaucracy hampers any effort for quick responsiveness and innovation regarding the lean six sigma application (Hussein et al., 2017). Meanwhile, the leadership style adopted in this organization didn't have any strategic vision. It is also authoritarian in its management manifestations and discouraging any participative decision making process. Then, the leadership impetus regarding quality enhancement techniques is incongruous. So, the managerial adage in such bureaucracy opposes team working and cooperation; whereby the espoused organizational culture hinders knowledge sharing, employee empowerment, visibility, enhancement methodology and creativity (Mostafa, 2005). Therefore, the workshops and on job training programs relevant for Lean Six Sigma application are very rare.

Social and cultural barriers: Opposition to change and incapability to endure enhancements are the most common social challenges (McNabb \& Sepic, 1995). As the government, mass communication institutes and civil society establishments didn't endorse or adopt the notion of quality management techniques as Lean Six sigma methodology and its vigorous role to boost the efficacy of public health care services. Then unfortunately, the societal culture ponders time dedicated to enhancement to be fruitless.

\subsection{Essential Requirements to Apply the Proposed LSS Framework}

Lean Six Sigma is still in its primary stages in healthcare in developing countries especially in Egypt as its public healthcare system faces various barriers -as it is mentioned previouslythat impede its ability to adopt an adequate policy to apply the LSS framework necessary to boost such system. Therefore, the government must adopt some reforming policies as prerequisites to the public healthcare system - relying on the aforementioned essentials of the integrated framework for Lean Six Sigma methodology, the recent new public management (NPM) and new public service principles, and good governance indices to overcome such barriers -to pave the way to induce the application of proposed LSS methodology framework to the Egyptian public healthcare system; whereby process enhancement, waste decrease, lead/cycle time diminution and medical errors cutback will be the key benefits. Such proposed requirements are as follows: 


\section{Mll Macrothink}

Journal of Public Administration and Governance

ISSN 2161-7104

2020, Vol. 10, No. 1

Top management commitment: It is obvious that management commitment to a Lean Six Sigma enhancement policy must surpass mottos, posters, or stimulus sermons. The leadership team should emanate an endurance of purpose, accompanied by strictness and tolerance that ease the foundation of such program (Yaduvanshi et al., 2017). The management team had to be liable and accountable for jointly handling the organization and enhancing its efficacy (Mehdi, 2005).Then, Leaders must be committed to lean six sigma framework by appointing lucid vision, goals and policies for adequate lean six sigma process. Furthermore, they had to endorse participative leadership by adopting role modeling method to implant lean six sigma methodology throughout the organization.

\section{Communicating the vision to all stakeholders}

As stakeholder participation is vital, all involved parts must be retained alongside the Lean Six Sigma enhancement program's progress be forehand. This communication must likewise tackle the substantial yields that would build up each stakeholder, whilst evading vows that cannot be achieved. The expression "under promise and over deliver" is proper. Premature communication with staffs is a must. But management must be mindful that not all employees have admittance to the same communications instruments as management (Radwan, 2018). For instance, some employees might not be given an e-mail account or a mailbox. Once the communication is instigated, feedback from employees should be fostered because in many instances, an application facet can simply be altered to embrace the desires of a stakeholder group (Sanders \& Hild, 2000). The leadership team must be implicated in a lucid, persuasive, and uttered way. Visiting different locations, devoting time in each training trend, and pervading in project encounters are instances of leadership act that signs their commitment. Scrutinizing development on a monthly foundation via Lean Six Sigma standing reunions may likewise be deemed. As projects begin, exhibiting the outcomes internally by placards or other noticeable means, positioned mainly in a communal work place, is worthy (Maleyeff, 2014). Some external stakeholders, such as contractors, support groups, and normal citizens can aid in diffusing the mission of lean six sigma program if they can be persuaded that the program is in their egocentricity.

\section{An adequate organizational and administrative system}

The formation of a reliable logical and thoughtful basis, backed by a supplementary organizational and administrative system, is crucial. The organization had to concentrate on the organizational and administrative system with which they are accustomed, because such system is equally vital as a coherent and feasible implementation strategy. The effective implementation of Lean Six Sigma programs can accompany other pervasive methods such as the Malcolm Baldrige National Quality Award standards or Total Quality Management (Harwick \& Russell, 1996; Daly, 2002). The basis should be simple to comprehend but not be lessened to cants. Thus, effective programs don't share a system, but a joint set of tenets (Andersson, 2006). For instance, they deem citizens to be clients instead of irritations. And they likewise consider that personal staffs can render a change by producing thoughts that can aid management create affirmative alteration (Bisgaard \& Freiesleben, 2004). External advisers may be useful throughout prior phases of program application. But they can 
similarly be an impediment when their method is contradictory with the organization's ethos or when they are considered liable for the program's effectiveness (Achanga et al, 2006).Therefore, lean adaptive organizational structure is vital to define appropriate roles and responsibilities for lean six sigma implementation. Additionally, such organic structure had to be responsive and adaptive to any change. Then, training needs to improve teamwork skills are essential (De Koning et al., 2006). They had to be consistent with the LSS programs and delivered in a just-in-time mode; which permitting employees to instantly employ efficiently and effectively the notions and methods enclosed (Maleyeff, 2014). Moreover, the formation of a mutual language, tactic, and toolbox will boost communication all over the organization. The organizational and administrative system, though, cannot be seen as unyielding (Park \& Gil, 2006). It should be permitted to develop and change as circumstances alter, such as throughout periods of organization yield.

\section{Building supportive workforce by removing fear}

To get and uphold organizational extensive backing, the organizations had to face the fear that will unavoidably escort Lean Six Sigma programs instigation. This fear is mostly owing to job insecurities, involving the likelihood of dismissals or reprimand for talking fairly throughout project meetings. The organization must be mindful of the actual necessity for employee commitment (De Koning et al., 2006). So, nevertheless it might seem that decreasing costs through enhancement will only happen with dismissals or other payroll reductions, effective programs concentrate on employing standard abrasion to diminish operating costs. Thus, a lucid statement must be set by the leadership team of employees assuring that no dismissals will occur as a consequence of a process enhancement action. In some circumstances, for instance, official consensuses among labor union, syndicates and management were adjusted to include the no dismissal assurance (Connor, 1997). As time goes, it must turn out to be obvious to union associates and other employees that certainly they can profit from Lean Six Sigma. In instance, their job satisfaction will rise as they are permitted to share in deciding how their job is made (Perry et al, 2006). One more advantage to jointly management and employees could be certainty that the efficiency and effectiveness of their processes likens positively with those in the private sector, removing worries of privatization. Clarity is crucial so as to employees (Maleyeff, 2014). Hence, it is acclaimed that propositions generated throughout project encounters that concern quality of work life be grasped earnestly.

\section{Maintaining a long-term cultural change}

Slow but stable application is usually favored than a huge change that may bestow arise to a "this only a matter of time and it shall go" inert belligerent response. Throughout this time, management at all levels should constantly strengthen an emphasis on "process" by evading the habit of ascribing responsibility for initial problems that take place. Managers should permit employees to dedicate some care to enhancing their performance along with the fulfillment of their tasks (Kim et al, 1995). Furthermore, employees must see that palpable gains can be acquired from their involvement in enhancement exertions. Then, when managers and employees on a project team are considered as counterparts, the boundary 
splitting their liability smears (Caldwell, \& Stuenkel, 2008).

Employees esteem their ability to handle how their tasks are done. Meanwhile, managers cherish having workforce who are stimulated to deliver outstanding service to customers. Staff at all levels who are parts of a process enhancement team that suggests development propositions; have a native aspiration to observe that their thoughts yield positive outcomes. Upholding impetus is crucial as the culture must be permitted to develop innately (Womack et al., 2003). Errors are probable, particularly failing in conveying the program's intents. In one circumstance, when Lean was presented into an organization, hearsay instigated that Lean denoted "Fewer Employees Are required." In these occasions the organization had to make hasty and conclusive act. Normally an emphasis on quantitative measures can be futile (Smith, 2003). For instance, a deceptively logical arrangement -The majority of staff trained in Lean Six Sigma - mostly makes an emphasis on training program itself rather than training main aim for enhancement (Raghu \& Geo, 2017). Haphazard time limitations or schedules can also be useless because situations vary and the program must not be imposed on the organization.

\section{Societal consciousness of Lean Six Sigma methodology}

Numerous sessions and media campaigns in Egypt should be arranged and achieved to inform the community about lean six sigma methodology main role in the fulfillment of enhancement objectives and its positive impact on the performance of service enterprises as healthcare institutions (Yaduvanshi et al., 2017). Consequently, any potential resistance for lean six sigma framework adoption can be avoided, and likewise to render organizations in the society mindful about relevant lean six sigma recent techniques.

\section{Advocated legislations and policies to lean six sigma applications}

Legislations, policies and regulations that advocate the application of lean six sigma methodology to the Egyptian healthcare had to be issued as soon as possible. Therefore, the emerging public agency for accreditation and quality control - established according to the newly law no. 2 of comprehensive healthcare insurance system issued at 2018 - had to emanate some decisive policies and regulations to impose the application of lean six sigma methodology to enhance the quality performance of Egyptian public healthcare institutes. Meanwhile, the ministry of healthcare associated with the ministry of finance in Egypt had to support such mission by enabling -via various technical, economic and financial incentivesthe adoption of lean six sigma techniques by the management of public healthcare institutions; to boost public healthcare system in Egypt.

\section{Conclusion}

It is noted after the preceding analysis that Egyptian public health care system had to be enhanced and transformed into an effective public health care service sector, able to augment productivity, enhance quality, decrease costs, increase speed, make a harmless environment for patients and workforce and surpass customer prospects. Then, an amalgamation of both Lean and Six Sigma can deliver the notion and the effective instruments to resolve problems and make speedy conversional enhancement at inferior cost to the health care system. 
Furthermore, combining Lean and Six Sigma produces a win-win situation. Lean Six Sigma application needs a great top level management commitment. But in developing countries - as Egypt- it is rare.

Accordingly, adopting the aforementioned essentials to build an integrated framework for Lean Six Sigma able to boost the health care service system is crucial. Such effectiveness essentials can be briefed as: A structured approach, project-based deployment, organizational competency development, organizational anchoring of solutions and linking strategy with project selection. Then recently, private firms and groups are setting many of health paradigms for the elaboration of the lean philosophy particularly in resource restricted situations in the developing and emerging economies. The literature review proposes that the implementation of lean and Six Sigma-based performance enhancement techniques yield positive financial and operational outcomes.

Unfortunately, there are diverse barriers -as we aforementioned- that may impede the adoption of lean six sigma framework to the Egyptian public healthcare system; that can enable the public hospitals to bring world-class quality treatment at reasonable price as well releasing operational efficacy with restricted resources. With the escalating corporatization of health and hospital sector, financial feasibility and stability is the issue of today; likewise in the government sector hospitals fighting for finance, accountability and operational efficacy necessities to be developed. Then, such barriers can be abbreviated as follows: Legal barriers, institutional barriers managerial and organizational barriers, financial problems, human resource barriers, scarcity of healthcare Quality research and social and cultural barriers.

Consequently, the Egyptian government must adopt some reforming prerequisites to the public healthcare system relying on the aforementioned essentials of the integrated framework for Lean Six Sigma methodology, the recent new public management (NPM) and new public service principles, and good governance indices to overcome the aforementioned barriers; and pave the way to induce the LSS methodology framework to the Egyptian public healthcare system; whereby process enhancement, waste decreasing, lead/cycle time lessening and medical errors diminishing will be the main advantages. Such proposed requirements are as follows: Top management commitment, communicating the vision to all stakeholders, an adequate organizational and administrative system, building supportive workforce by removing fear, maintaining a long-term cultural change, societal consciousness of Lean Six sigma methodology and advocated legislations and policies to lean six sigma applications.

Finally, Egypt aims recently to make the change to a healthcare quality culture (as contradicted to a fiscally managed healthcare culture of the government) to make a healthier populace according to its sustainable development vision 2030; advocated by the commitment of the political leadership. Therefore, the deficiencies restraining nature of Lean Six Sigma programs in health and hospital will gain more importance. Eradicating flaws and inadequacies in the provision of health care will finally yield an enhanced health care service. The Egyptian government tends to realize such aim at an inferior cost with superior reliability, quality and carefulness. Hence, the investments in cultural quality conversions, such as Lean 
and Six Sigma will significantly be increased in the next decade. It has occurred through the manufacturing field. It is nowadays grabbing interest in the provision and creation of health care services by decreasing deficiencies, improving customer service and generally diminishing costs through the board and accomplishing delight for operational efficacy in the public health care system.

\section{References}

Achanga, P., Shehab, E., Roy, R., \& Ne, G. (2006). Critical success factors for lean implementation within SMEs. Journal of Manufacturing Technology Management, 17(4), 460-471. https://doi.org/10.1108/17410380610662889

Al-QatawnehLina, A. A. A., \& Zalloum, S. S. Z. (2019). Six Sigma Application in Healthcare Logistics: A Framework and A Case Study. Journal of Healthcare Engineering, 1-12. https://doi.org/10.1155/2019/9691568

American Society for Quality. (2009). The ASQ hospital study: Hospitals see benefits of lean and Six-Sigma. Retrieved from http://www.asq.org/mediaroom/press releases/2009/20090318-hospitals-seebenefits-lss.htmlaccessed at 4/10/2019

American Society for Quality. (2009). The ASQ hospital study: Hospitals see benefits of lean and Six-Sigma. Retrieved from http://www.asq.org/mediaroom/press-releases/2009/20090318-hospitals-seebenefits-lss.html accessed at 9/10/2019.

Andersson, R., Eriksson, H., \&Torstensson, H. (2006). Similarities and differences between TQM, six sigma, and lean. The TQM Magazine, 18(3), 282-296. https://doi.org/10.1108/09544780610660004

Antony, J., \& Coronado, R. B. (2001). A strategy for survival. Manufacturing Engineer, 80(3), 119-121. https://doi.org/10.1049/me:20010308

Baczewski, R. (2005). Four methods for improving performance: A comparison. Healthcare Financial Management, 59(7), 101-102.

Bisgaard, S., \& De Mast, J. (2006). After Six Sigma-What's next? Quality Progress, June, 39, 57-62.

Bisgaard, S., \& Freiesleben, J. (2004). Six Sigma and the bottom line, Quality Progress, September, 37, 57-62.

Bortolotti, T., Boscari, S., \& Danese, P. (2015). Successful lean implementation: Organizational culture and soft lean practices. International Journal of Production Economics, 160, 182-201. https://doi.org/10.1016/j.ijpe.2014.10.013

Breyfogle III, F. W. (2003). Implementing six sigma: smarter solutions using statistical methods. John Wiley \& Sons.

Caldwell Jr, C., \& Stuenkel, K. M. (2008). Moving from good to best in healthcare: embracing accounting in improvements. Healthcare executive, 23(3), 8. 


\section{MInstitute Macrothink $^{\text {Int }}$}

Journal of Public Administration and Governance ISSN 2161-7104

Central Agency for Public Mobilization and Statistics (CAPMAS) (2017). Anonymous, Egypt in Figures, Arab Republic of Egypt. Available at:http://www.capmas.gov.eg/Pages/StaticPages.aspx?page_id=5035 accessed at 2/9/2019.

Charles, J., Allen, R., Sonderman, T., \& Wedgwood, I. (2008). Attacking waste \& variation hospital-wide: Acomprehensive lean sigma deployment. Available at:http://www.iienet.org/uploadedFiles/SHS/Lean\%20Sigma\%20Deployment\%20Columbus \%20Regional\%20Hospital\%20Charles\%20Johnson.pdf accessed at 9/8/2019.

Connor, P. E. (1997). Total quality management: A selective commentary on its human dimensions, with special reference to its downside. Public Administration Review, 501-509. https://doi.org/10.2307/976961

Cronemyr, P. (2007). DMAIC and DMADV-differences, similarities and synergies. International Journal of Six Sigma and Competitive Advantage, 3(3), 193-209. https://doi.org/10.1504/IJSSCA.2007.015065

Daly, J. L. (2002). Implications of organizational climate and ethical leadership on reengineering in municipal government. Public Administration Quarterly, 26(2), 198-217.

De Koning, H., \& De Mast, J. (2006). A rational reconstruction of Six-Sigma's breakthrough cookbook. International Journal of Quality \& Reliability Management, 23(7), 766-787. https://doi.org/10.1108/02656710610701044

Does, R. J., Vermaat, T. M., de Koning, H., Bisgaard, S., \& van den Heuvel, J. (2006). Standardizing healthcare projects. Lean \& Six Sigma Review, 6(1), 14.

Durant, R. F., Kramer, R., Perry, J. L., Mesch, D., \& Paarlberg, L. (2006). Motivating employees in a new governance era: The performance paradigm revisited. Public Administration Review, 66(4), 505-514. https://doi.org/10.1111/j.1540-6210.2006.00611.x

Fairbanks, C. B. (2007). Using Six Sigma and Lean methodologies to improve OR throughput. Aorn Journal, 86(1), 73-82. https://doi.org/10.1016/j.aorn.2007.06.011

Folaron, J., \& Morgan, J. P. (2003). The evolution of six sigma. Lean \& Six Sigma Review, 2(4), 38.

George, M. L. (2003).Lean Six Sigma for Service. New York, NY: McGraw-Hill, 44-47.

Gottfredson, M., \& Aspinall, K. (2005). Innovation versus complexity: What is too much of a good thing? Harvard Business Review, 83(11), 62-71, 164.

Graves, A. (2014). Lean Six Sigma: Endless Possibilities in Healthcare. Available at: https://www.sixsigmadaily.com/lean-six-sigma-endless-possibilities-in-healthcare accessed at 21/9/2019.

Harry, M., \& Schroeder, R. (2006), Six Sigma: e breakthrough Management Strategy Revolutionizing the World's Top Corporations, Doubleday, New York, NY, USA, 78-83.

Harry, M. J. (1997). The vision of Six Sigma (5th ed.). Phoenix: Tri Star, 35-38. 
Harwick, B. T., \& Russell, M. (1996). A working model to help institutionalize quality improvements in local governments. The International Journal of Public Administration, 19(10), 1891-1913. https://doi.org/10.1080/01900699608525169

Henderson, K. M., \& Evans, J. R. (2000). Successful implementation of Six Sigma: benchmarking general electric company. Benchmarking: An International Journal, 7(4), 260-282. https://doi.org/10.1108/14635770010378909

Hussein, N. A., Abdelmaguid, T. F., Tawfik, B. S., \& Ahmed, N. G. (2017). Mitigating overcrowding in emergency departments using Six Sigma and simulation: A case study in Egypt. Operations Research for Health Care, 15, 1-12. https://doi.org/10.1016/j.orhc.2017.06.003

Juran, J. M. (1989). Juran on leadership for quality. New York: Free Press, 42-47.

Kim, P. S., Pindur, W., \& Reynolds, K. (1995). Creating a new organizational culture: the key to total quality management in the public sector. International Journal of Public Administration, 18(4), 675-709. https://doi.org/10.1080/01900699508525027

Kowalik, K. (2018). Six Sigma as a method of improving the quality of service process. Production Engineering Archives, 19(19), 10-15. https://doi.org/10.30657/pea.2018.19.03

Kwak, Y. H., \& Anbari, F. T. (2006). Benefits, obstacles, and future of six sigma approach. Technovation, 26(5-6), 708-715. https://doi.org/10.1016/j.technovation.2004.10.003

Lippincott Solutions. (2017). Lean Six Sigma for Healthcare Quality Improvement, Created $\begin{array}{llll}\text { Aug } & 11 & 2017 . & \text { Retrieved from }\end{array}$ http://lippincottsolutions.lww.com/blog.entry.html/2017/08/11/lean_six_sigma_forh-Ycvm.ht $\mathrm{ml}$ accessed at 10/9/2019

Maleyeff, J. (2006). Exploration of internal service systems using lean principles. management decision, 44(5), 674-689. https://doi.org/10.1108/00251740610668914

Maleyeff, J. (2014). Sustaining public sector lean six sigma: perspectives from North America. Management and Organizational Studies, 1(2), 92-99. https://doi.org/10.5430/mos.v1n2p92

Mazzocato, P., Savage, C., Brommels, M., Aronsson, H., \& Thor, J. (2010). Lean thinking in healthcare: a realist review of the literature. BMJ Quality \& Safety, 19(5), 376-382. https://doi.org/10.1136/qshc.2009.037986

McNabb, D. E., \& Sepic, F. T. (1995). Culture, climate, and total quality management: Measuring readiness for change. Public Productivity \& Management Review, 369-385.

Mehdi, M. A. Lean Six Sigma: an Overview for Developing Countries. In POMS Conference paper https://www. pomsmeetings.org/confpapers/005/005-0043.pdf.

Monden, Y. (1993). The Toyota Production System (2nd Edition.). Norcross, VA: Industrial Engineering and Management Press. https://doi.org/10.1007/978-1-4615-9714-8 


\section{Macrothink}

Journal of Public Administration and Governance

ISSN 2161-7104

Mostafa, M. M. (2005). An empirical study of patients' expectations and satisfactions in Egyptian hospitals. International Journal of Health Care Quality Assurance, 18(7), 516-532. https://doi.org/10.1108/09526860510627201

Nair, R. P., \& Paul, G. Lean six sigma as a panacea to improve service quality in medical tourism.

Park, S., \& Gil, Y. (2006). How Samsung transformed its corporate R\&D center. Research-Technology Management, $\quad$ 49(4), 24-29. https://doi.org/10.1080/08956308.2006.11657384

Pyzdek, T. (2001). The Six Sigma handbook-A complete guide for greenbelts, blackbelts, and managers at all levels, New York: McGraw-Hill, 24-28. https://doi.org/10.1504/IJSSCA.2004.005275

Pyzdek, T. (2004). Strategy deployment using balanced scorecards. International Journal of Six Sigma andCompetitive Advantage, 1(1), 21-28.

Pyzdek, T., \& Keller, P. (2014), e Six Sigma Handbook, McGraw-Hill Education, New York, NY, USA, 4th edition, 101- 108.

Radwan Mahmoud Abdel Fattah (2018). Lean six sigma methodology in Saudi healthcare organizations: Drawing the topography of an unexplored territory, GPHC \& Nutrition \& Healthcare congress October 18-20, Paris, Journal of Nutrition \& Food Sciences, Vol. 8, 3-9.

Sanders, D., \& Hild, C. (2000). A discussion of strategies for Six Sigma Implementation. Quality Engineering, 12(3), 303-309. https://doi.org/10.1080/08982110008962593

Schroeder, R. G., Linderman, K., Liedtke, C., \& Choo, A. S. (2007). Six Sigma: definition and underlying theory. Journal of Operations Management, 26(4), 536-554. https://doi.org/10.1016/j.jom.2007.06.007

Shankar, R. (2009), Process Improvement Using Six Sigma: A DMAIC Guide, ASQ Quality Press, Milwaukee, WI, USA, 65-72.

Shingo, S. (1989). A study of the Toyota production system. New York: Productivity Press, 51-56.

Smith, B. (2003). Lean and Six Sigma-a one-two punch. Quality progress, 36(4), 37-41.

Snee, R. D. (2005). When worlds collide: lean and six sigma. Quality Progress, 38(9), 63-65.

Standard, C., \& Davis, D. (1999). Running today's factory: a proven strategy for lean manufacturing. Hanser Gardner Publications.

Womack, J. P., James, P., \& Daniel, T. J. (2003). Lean Thinking. New York, Free Press, 78-89.

Womack, J. P., Jones, D. T., \& Roos, D. (1990). The machine that changed the world: The story of Lean production. New York: Rawson Associates, 88-95. 


\section{Macrothink}

Journal of Public Administration and Governance ISSN 2161-7104

Womack, J. P., Jones, D. T., \& Roos, D. (1991). The Machine That Changed the World. New York, NY: HarperCollins Publishers, 63-69.

Womack, J., \& Jones, D. (2003). Lean thinking: Banish waste and create wealth in your corporation (Revised \&Updated). New York: Harper Business, 53-59.

World Health Organization (2011). Anonymous, Country office for Egypt. Retrieved from

Yaduvanshi, D., \& Sharma, A. (2017). Lean six sigma in health operations: challenges and opportunities - 'Nirvana for operational efficiency in hospitals in a resource limited settings'. Journal of Health Management, 19(2), 203-213. https://doi.org/10.1177/0972063417699665

Zineldin, M. (2006). The quality of health care and patient satisfaction: an exploratory investigation of the 5Qs model at some Egyptian and Jordanian medical clinics. International journal of health care quality assurance, 19(1), 60-92. https://doi.org/10.1108/09526860610642609

Zu, X., Fredendall, L. D., \& Douglas, T. J. (2008). The evolving theory of quality management: the role of Six Sigma. Journal of operations Management, 26(5), 630-650. https://doi.org/10.1016/j.jom.2008.02.001

\section{Copyright Disclaimer}

Copyright for this article is retained by the author(s), with first publication rights granted to the journal.

This is an open-access article distributed under the terms and conditions of the Creative Commons Attribution license (http://creativecommons.org/licenses/by/4.0/). 